\title{
Knowledge Management in Action
}

\section{A Study of Knowledge Management in Management Consultancies}

\author{
Jacoby Petersen, Nicoline; Poulfelt, Flemming
}

Document Version

Final published version

Publication date:

2002

License

CC BY-NC-ND

Citation for published version (APA):

Jacoby Petersen, N., \& Poulfelt, F. (2002). Knowledge Management in Action: A Study of Knowledge

Management in Management Consultancies. LOK Research Center. CBS. LOK Working Paper No. 1/2002

Link to publication in CBS Research Portal

\section{General rights}

Copyright and moral rights for the publications made accessible in the public portal are retained by the authors and/or other copyright owners and it is a condition of accessing publications that users recognise and abide by the legal requirements associated with these rights.

Take down policy

If you believe that this document breaches copyright please contact us (research.lib@cbs.dk) providing details, and we will remove access to the work immediately and investigate your claim. 


\title{
Knowledge Management in Action: A Study of Knowledge Management in Management Consultancies
}

\author{
Nicoline Jacoby Petersen \\ np.lpf@cbs.dk \\ Flemming Poulfelt \\ fp.lpf@cbs.dk \\ Copenhagen Business School \\ Department of Management, Politics \& Philosophy \\ Blaagaardsgade $23 \mathrm{~B}$ \\ 2200 Copenhagen $\mathrm{N}$ \\ Denmark \\ Phone: +4538153630
}

\begin{abstract}
Published in:
Anthony F. Buono (ed.): "Developing Knowledge and Value in Management Consulting." Volume 2: Research in Management Consulting.

Greenwich: Information Age Publishing, 2002.
\end{abstract}

\begin{abstract}
The chapter focuses on knowledge management and on knowledge sharing in particular. It is based on a study of a wide range of management consulting firms in Denmark. The purpose of the study has been to gain a more profound understanding of what constitutes knowledge sharing in practice. What does knowledge sharing imply? What are the organizational and managerial aspects affecting knowledge sharing and how? Findings from the study demonstrate a series of critical issues related to knowledge sharing: the importance of having a knowledge strategy, the relation between the project organization, power and mobility, the role of office space, the quest for time, the problem of decontextualization in electronic databases, the need for incentives different from financial and promotional ones, the importance of trust among employees, and the necessity of top management support.

Based upon the empirical findings, we develop a knowledge sharing typology. This framework suggests that the concept of knowledge sharing includes six dimensions:
\end{abstract}


knowledge storing, knowledge distribution, knowledge exposure, knowledge transfer, knowledge exchange and knowledge collectivism. 


\section{INTRODUCTION}

This chapter is a result of a research project on the production and application of management knowledge in the Danish management consulting industry. Knowledge management is becoming an increasingly important topic in management philosophy and as a management tool as reflected in the growing number of articles and books on the issue. The article database Proquest, ${ }^{1}$ for example, contained 45 articles about knowledge management in 1995. By the beginning of 2002, the number has increased to approximately 2000. In 1997, two new journals - the Journal of Knowledge Management and Knowledge and Process Management - were introduced, and in 2000, the Journal of Intellectual Capital emerged. During this same period the number of organizations venturing into the knowledge management arena has grown as well. While some industries have been highly proactive in this area - particularly consulting, information technology and related advisory-based industries where knowledge is the key resource - knowledge management initiatives are becoming increasingly prominent throughout the corporate landscape.

While the knowledge management literature offers some useful insights, many issues (e.g., what is the actual value of implementing knowledge management activities?) remain unclear. In an attempt to begin to fill this void, our research focused on three concerns: (1) the various strategies companies pursue in the knowledge management area, (2) what effect(s) these strategies have on the firms and their members when they are implemented, and (3) the underlying reasons (in terms of explanations rather than causal factors per se) that could clarify some of the dynamics and mechanisms involved in this developing field. In the beginning, knowledge management was all about technology and the new possibilities that company Intranets, e-mail systems and databases could provide. Today, the view of knowledge management has shifted toward broader social and cultural factors, with technology now seen as an enabling factor. Why has this shift occurred? What differences can be found among employees who have been exposed to a technological approach alone and those who have experienced broader exposure to knowledge management practices?

One aspect of knowledge management that has been well accounted for is the concept of knowledge itself. It has been outlined in a number of different ways, from the classical philosophical perspective as "justified true belief" to a more pragmatic view as "for action" (Davenport \& Prusak, 1998; Christenen, 2001). At the same time, knowledge has become an umbrella for many different words - including data, information, wisdom, codified, personal, proprietary, common, organizational, diffused, migratory, embedded, embodied, encultured, embrained, tacit, explicit, sticky, and so forth (cf. Badaracco, 1991; Blackler, 1995; Boisot, 1996; Polanyi, 1958; Nonaka \& Takeuchi, 1995; Saint-Onge, 1996; Von Hippel, 1990). Is it just as easy to find several definitions of knowledge sharing in the knowledge management literature? The quick answer is "No."

Knowledge management is about developing, sharing and applying knowledge within an organization to gain and sustain competitive advantage. The concept of knowledge sharing, however, is not been well defined. The ambiguity in the concept, for instance, is reflected in some of the major anthologies about knowledge management published in recent years, from Cortada and Wood's (2000) Knowledge management Yearbook 2000-2001, to Little, et al's (2002) Managing Knowledge reader to Dierkes, et al's (2001) Handbook of organizational Learning and Knowledge. These volumes do not contain any articles dealing specifically with knowledge sharing, knowledge transfer, knowledge distribution, knowledge diffusion and the like - and there are few references in the subject index. Even considering the exponential explosion of knowledge management-related articles in Proquest since 1995, less than 5 percent are linked to the keyword "knowledge sharing." 
This apparent void does not mean that knowledge sharing as such is completely absent. A dichotomy between technology and human beings, electronic distribution and human interaction, and IT and HR is often embedded (see, for example, Davenport \& Prusak, 1998; Hansen, 1999). These ongoing discussions deal with the question of what kind of knowledge processes we should focus on and where in the organization the knowledge project should be rooted.

The main tensions surrounding the technological aspects of knowledge management (KM) focus on the issue of tacit knowledge and how to capture it in knowledge management systems, as well as the challenge of motivating employees to contribute to these systems. Quality control and updating are issues often raised. Globalization, in contrast, often emphasizes the human dimension, especially in terms of lags in time and space, and the challenges involved in creating a culture of knowledge sharing as opposed to one of knowledge hoarding.

The purpose of this chapter is to create a more profound understanding of what constitutes knowledge sharing in practice, focusing on two key questions:

- What is actually meant by knowledge sharing?

- What organizational and managerial aspects affect knowledge sharing and how?

The analysis is mainly empirically oriented, examining the empirical data primarily from a "common sense" perspective (Kvale, 1997) and drawing on various theoretical elements in the knowledge management field. Nine issues are identified as important elements in the knowledge-sharing processes in the sample firms. These issues will be highlighted and used to develop a knowledge sharing typology. This framework suggests that the concept of knowledge sharing includes six dimensions: knowledge storing, knowledge distribution, knowledge exposure, knowledge transfer, knowledge exchange and knowledge collectivism.

\section{THE RESEARCH}

The empirical part of the study provided data from a variety of consultancies. Seven management consulting firms participated, including both major international consultancies and medium-sized, Danish-based management consulting firms. Furthermore, information (mainly interview transcriptions) from an additional three management consulting firms and two consulting-engineering firms is included as a secondary source. ${ }^{2}$ These data are a relevant supplement to our primary data source, and they provide an interesting comparative perspective, as both engineers and management consultants have similar types of businesses within the consulting industry. Both kinds of firms are knowledge firms in the sense that they primarily make their living from vending knowledge. As such, knowledge management is vital for these firms and, as we will see, both engineering and management consulting firms experience a number of common problems in this area.

The number of contacts and type of data generated in each of the companies in our sample varied according to the amount of access we were given, the extent of their willingness to participate in the research, and the time they allocated to us. Furthermore, the contacts were on different levels in the organizations; we have talked with top management, employees, and organizational members who specifically worked with knowledge management, either internally or externally in connection with client projects. In each organization, we attempted to interview people at all levels in each company to get an idea of the contrast between the firms' visions (top management) and the actual performance (the employees) of the organization.

The data are based on semi-structured, tape-recorded interviews and comprehensive notes taken at company meetings. The study also employed an experimental methodology in 
three of the firms - organizational photography. In these three firms, the researcher walked around in the organization for a day, taking approximately one hundred photos. A selection of the photos were then arranged in six to seven series of four pictures. A group of employees (approximately four in each focus group) were shown the photos, and asked to discuss knowledge sharing in their company, associating from the photo series. The focus group was exposed to a new series of pictures every twelve minutes, and the researcher remained silent during the one and one half-hour session. The discussion was tape-recorded and transcribed like normal interviews.

The idea underlying this approach to data gathering is to get another view of what constitutes knowledge sharing in a particular organization. When using semantic questions (like in face-to-face interviews) instead of visual ones (like the photos), the answers are more likely to fall within the framework of the researcher. By using photos rather than asking questions to prompt people to talk about themselves and their everyday working life, the researcher may receive unanticipated responses - even answers to questions the researcher might not have thought of asking. ${ }^{3}$ Using photos, the discussion opens a number of new avenues with respect to the understanding of knowledge sharing in practice.

Table 1 summarizes the different types of information that were gathered in the study. In addition to the interviews, meetings and focus groups, the study also drew on publicly accessible material about the firms, e.g. their web sites, financial figures, and various publications published by some of the firms on their knowledge management practices.

\begin{tabular}{|l|c|c|c|c|}
\hline & Interviews & Meetings & Focus groups & Secondary mat. \\
\hline Management & & 3 & & 6 \\
\hline Employees & 5 & & 3 & 18 \\
\hline KM-employees & 3 & 1 & & 4 \\
\hline Total & & & & $\mathbf{2 8}$ \\
\hline
\end{tabular}

Table 1: Research overview

\section{TO HAVE A KNOWLEDGE STRATEGY - OR NOT}

The research shows that large management consulting firms have invested heavily in technological knowledge systems, attempting to bring proximity into the global firm, which operates across time and space. There are, however, less well-considered concerns regarding informal knowledge sharing, an issue that several of the consultants in our study noted as a problem. While small management consulting firms may be in a better position to share knowledge informally by virtue of their size, they often operate with a minimum of technology for handling knowledge that in many cases is inadequate. The employees keep their material in private binders, and the consultants increasingly see this lack of common structure as a source of annoyance. Kent Greenes (in Andresen \& Jakobsen, 1999) points to 
the fact that small firms are not focusing on knowledge management to the same extent as larger firms, because of the belief that "everybody talks with each other." This assumption is, in many cases, erroneous and thus becomes a barrier to directing appropriate focus on knowledge management.

Although some of the participating management consulting firms in our sample did have an explicit knowledge strategy, others did not. This observation does not necessarily imply that those firms with a formulated strategy are more focused on knowledge sharing and knowledge development, and that those without such a strategy have not reflected on the subject nor implemented initiatives to encourage knowledge sharing. Many firms have activities the primary objectives of which are not necessarily knowledge sharing, but in practice have this "side effect." The opposite may also be the case in firms with an explicit strategy - it is only (empty) words that are not transformed into action. And finally there are firms with a knowledge strategy that try to "walk the talk."

Studies show (e.g., Foote, et al, 2001; Storey \& Barnette, 2000) that knowledge management projects often fail because of a lack of a knowledge strategy, a weak relation to the business strategy of the company, and/or a weak anchor and link to the rest of the organization. Other studies show that knowledge management works better in firms with an explicit knowledge strategy, appropriately supported by structure, culture, technology and management (see Apostolou \& Mentzas, 1999; Hauschild, et al, 2001; Kluge, et al, 2001). explained:

These findings correspond well with our observations. As one of our respondents

Our business is divided into four mega processes: sales, service, people, and knowledge. These four mega-processes saturate the entire organization and a number of employee forums have been established. For example, I am a member of the service forum, where we concentrate on the services that we supply. What are our methodological tools, how can we improve and refine them, what is missing today? We then put our ideas into action and communicate them to other areas of the organization if the given issue lies outside our domain. [...] I have the chance of getting to know a lot of things and become aware of the fact that the organization is working professionally on our training. Management is aware of our wish to improve our performance. We want to be better at doing what we are doing, and how can we do that? I find this is a big step. We are allowed to participate, to influence, to discuss how to become better, and how we can approach it, how we can affect routines in the organization and what else is needed. I like that."

This quote illustrates, among other things, that in organizations where KM is a basic part of the other business processes and daily practice, employees are more likely to understand the relation between knowledge management initiatives and the company mission.

While this point may seem obvious, not everyone necessarily shares this holistic perspective. The research shows, that knowledge management is not likely to succeed when sporadic initiatives within the knowledge field are launched without being integrated into the organization. As an example, the majority of companies today have an Intranet, and the most frequently used argument for having one is that it enables the knowledge sharing across organizational units. However, despite the growing existence of company Intranets, the problem most frequently mentioned when discussing knowledge sharing with employees is that they do not know what colleagues in other departments are working on. In other words, 
technological initiatives like Intranet and shared databases themselves are insufficient tools for furthering knowledge sharing.

The larger international management consulting firms appear to rely on a "rule governed" type of culture, where the mother organization abroad (typically based in U.S.A.) often dictates global company policies. Several employees working in international consultancies, for example, express the attitude of "that's just the way it is". They know that they have to comply with firm-based rules to make it all work, and accept that even small changes take a lot of time. This situation is not the case in smaller companies, as illustrated by the comments by a Human Resource manager in a medium-sized consulting firm:

The consultants hate centralism. It is difficult to make them report anything. They do not do it, and they do not care to. Here knowledge sharing grows out of local initiatives. There is no general strategy. Knowledge sharing is random.

In small management consulting firms, the consultants, to a large extent, work independently, i.e., each consultant develops, sells and delivers his or her own assignments. This reality, of course, is partly due to the fact that smaller consulting firms have smaller assignments that do not require a formal division of labor. In effect, such firms often develop into units of "one-man firms" in which everybody can do as they please - as long as they sell and deliver.

\section{The Relevance of Project Organizations}

In the absence of formal knowledge management policies, organizational structure can be an influential determinant of knowledge sharing. One of our respondents, for example, noted that:

The more people a job requires, the more knowledge the project organization accumulates - assuming that new teams are established now and then. For financial reasons, small jobs are one-man jobs, making it more difficult to disseminate knowledge.

This quote is interesting in relation to the role that a project organization structure plays in knowledge sharing. Our study shows that project organizations (or adhocracy in Mintzberg's (1983) terminology) have had a positive effect as a vehicle for knowledge sharing in several ways, as we will see in the following paragraphs.

Ever since Foucault concluded "it is not possible for power to be exercised without knowledge. It is impossible for knowledge not to engender power" (Allee, 1997) knowledge and power have been intertwined. However, the very aspect of power is surprisingly absent in our empirical data. This observation appears to reflect the project organization structure that is practiced in the majority of the management consulting firms.

\section{I have never seen it as a problem that you don't share knowledge because you simply have to do it...You cannot survive in [the firm] if you don't share your knowledge, you can't just sit in your office and say, 'This is my small world, or my confined domain.'}

The project organization, in which everyone in the project group is dependent on the work of each other and where success is measured by the quality of the joint efforts, makes it difficult to survive unless you co-operate and share knowledge with colleagues.

When advocating the usefulness of knowledge management, a rationale often heard is that when a competent or key employee leaves, the firm loses vital knowledge - and, in worst case scenario, part of its competitiveness (e.g., Hildreth, et al, 2000). With the growing mobility in the labor market, companies should give substantial attention to this problem, focusing on improving the conditions for knowledge sharing within the company. The dogma that knowledge sharing is a good idea due to the increasing mobility on the labor market, 
however, is apparently not of immediate importance to the management consulting business due to its project orientation. A consultant in one of the firms in our sample explains it as follows:

You seldom work alone on a project, so even though Robert is no longer here, then Michael is, and the two of them worked together. So if I can remember that they've worked on something which is relevant to me, Michael ensures that the information is available. Another employee pointed out:

One way or the other I do not think that we lose much knowledge.

We do lose some competent people, but I do not really think that they take a lot of knowledge with them when they leave. The

knowledge remains in-house - somewhere - and it keeps

accumulating. Even the tacit part of it will in most cases be shared, because you have been working [on a project] together. Only a few of those leaving the firm take critical knowledge with them.

This quote raises an interesting question: Are management consulting firms less dependent on unique competencies compared to engineering firms, where a company might win an assignment based on the expertise of one of its members (e.g., underwater asphalting)? One consultant noted

Our concepts are very overlapping. It's the way we work, 90 to

95\% [of what we do is based on] general knowledge and only a small part is specific. This means that what disappears [when an employee leaves the firm] may be an expertise, but the joined insights remain. So the joined quantity of knowledge is really quite large, larger than you would think.

These quotes suggest that the management consulting business might not require as specific qualifications as other kinds of professional services businesses, as might be found in the highly specialized requirements of engineer or lawyer consultants. In effect, the loss of any one consultant is not perceived as a loss of knowledge. A high degree of turnover, of course, poses a problem in relation to knowledge sharing (as well as many other problems). The period of introducing and socializing new employees can also be time consuming and expensive, and clients may decide to follow a particular consultant who has left the firm instead of staying with the company.

The problem of mobility appears to be more critical higher up in the hierarchy, where the consultant more often works alone. One management consulting firm experienced this when a key employee was given new assignments in the firm and no one could replace him. As they lamented, "we now know that every king needs a successor."

\section{The Role of Office Space}

The consulting firms in the study are organized very differently - from an office landscape to the farmhouse idyll associated with small one-man offices. There are extremely many - and different - opinions on the various models, but it is quite evident that the physical frames of the organization do influence knowledge sharing. Physical space and layout influence the way in which employees move around in the organization and thus whom they interact with during the day.

Several firms were quite aware of this relationship and have chosen to create an open office plan with flexible workstations. As illustrated by the following quite, several statements indicated this structural approach to knowledge sharing was a good idea:

You often hear something accidentally when you sit in the open office and then you think, 'I've done that before, let me give them 
some input'. You're not going to catch those situations if you sit isolated in your office. In fact, I think quite often that people from quite unexpected positions are able to offer input.

Other statements, however, point in different directions. The following example is from a focus group discussion:

- [In an open office] knowledge sharing can actually become an obstacle as you may be confronted with it all the time. You can meet a hundred people all the time. You are on your way to the lavatory, there are four people at the café table, and you haven't seen some of them for a while. What has happened since we last met, what are you doing, etc.? You can spend your entire day knowledge sharing, if that's what you want.

- I fully agree. I can tell you of a funny example from yesterday. I stopped by one of my colleagues, and he said: Hey, see what I am working on now. I spot some interesting problems - and I can't let it be because I'm curious - and I share my thoughts with him and propose to forward that mail to me so I can look it over. But what the hell - I don't have the time for it!

- And suddenly you've spent one and a half-hours on a colleague and you don't get home before eight o'clock that evening.

- It takes a lot of discipline.

As this dialogue suggests, although open office arrangements facilitate interaction and the resulting knowledge sharing that comes from person-to-person contact, it can become an allencompassing, time-consuming task. As a result, people can feel that it disrupts rather than facilitates accomplishing their tasks and objectives.

Several employees noticed that when working in an open office environment they always chose to occupy the same desks, and an informal way of organizing begins to emerge. In addition, there is the problem of noise and questions of inefficiency. In this context, Moberg's (1997) study of efficiency in open work places is interesting in because it demonstrated that even though the employees felt that their efficiency decreased, their overall productivity actually increased. Many people, however, feel that their creativity is restricted in open workspaces because of the high degree of consideration that needs to be demonstrated some of the respondents even talked about the atmosphere of a "burial chamber". In fact, many of these individuals reported staying at home if they needed to concentrate on a specific task, which might prove to be counterproductive in a culture where consultants already spend much of their time off-site with clients, thus leaving less time to interact with colleagues and be a part of the organization.

The dynamics associated with such (physical) unavailability might explain why so many consultants are enthusiastic about the idea of a project room, i.e., a room allocated to the entire project group as its "workplace" at the start of a new project. Respondents reported that they liked to take over a "completely naked" room with white walls, allowing the project group to "build their own world" with decorations, posters and pictures on the walls. One consultant said that, in the consulting business, employees do not function as a community working towards common goals, such as in traditional production companies where the common goal is to produce certain products. Such traditional, common goals constitute an "organizational kit" which is absent in the management consulting firm, where the product mainly consists of individual services. Furthermore, with frequent physical absence it becomes difficult to create the feeling of a community that is important to knowledge sharing. Project rooms seem to be a way of creating a feeling of "belonging."

Several respondents raised the question of whether it would be better to have a desk close to colleagues from the same department or to be physically closer to colleagues from other departments as a way of enhancing knowledge sharing. While being together with close 
colleagues provides one with security and ready access to create a community of practice, such proximity emphasizes the functional division of labor and confines the way in which individual consultants work together, possibly limiting the variety of methods used. One of the consultants in the study commented on the advantages of interdisciplinary workplaces:

We are four different departments and the mixing of departments is evidently advantageous. You talk and somebody listens -' Is that really what you are doing? We can help you out on that and that.' Such situations generate more knowledge sharing. If you are working in the same field professionally, you often use the same databases, identical material, and so forth. For example, I talked to Peter, and in his department they had some super material that I had never seen before. I discovered this by pure accident - just because we were sharing office space - and they heard what we were doing, 'Oh, that is what you are working with, we actually have something here....'

Finally it should be noted that most management consulting firms are not very good at using office space to show who they are, telling others about themselves and their products. There is an incredible amount of (trivial) art on the walls instead of plates, pictures and other symbols that could communicate knowledge within and about the firm. Corridors are obvious places to communicate such knowledge as the following quote illustrates:

In connection with [a project], I had a large colored poster on our door and a lot of our colleagues knocked on the door asking what it meant - 'what is it you have here? It sure looks interesting. Can we help, or would you tell us about it?' The effect it had....

Manufacturing companies always have showcases or exhibitions of products in public arenas, but in knowledge companies, where the production is more intangible, this dimension is often neglected. This is unfortunate as material objects do play a part in shaping the corporate identity - employees become aware of what goes on in the other departments and it is good public relations (PR), providing greater visibility when clients visit the firm.

\section{The Quest for Time}

It is well known that consultants are busy people. Time is - to draw on a rather stale cliché - "money." Consultants sell their knowledge by the hour, attempting to invoice as much time as possible to the client to enhance (human) resource utilization. Hours that cannot be invoiced to the client are regarded as costs - despite the fact that in the long run they might represent an investment of high return if, for example, the time is spent on research and development or an extension of skills and capabilities. Utilization is - in the words of one of our respondents - "the underlying value controlling all behavior." This perspective is not hard to understand when the consultant's bonus and promotions to a high degree depends on his or her utility value. As knowledge development and knowledge sharing activities are, to a large degree, regarded as internal activities (there are, of course, many examples of clients paying indirectly for this activity) striving for such utility becomes a fundamental barrier to efficient knowledge sharing.

It is surprising that only one management consulting firm expressed a specific attempt to resolve this problem:

One thing I wanted to abolish was the utilization rate, i.e., the foundation for our performance management system. Today everything [billable and non-billable hours] has become productive time... It is the day-to-day things, the fundamental techniques that create the employees you have. That is my starting 
point. It is the way in which you have to make your weekly

reporting, account for your time, invoice your time, and how you

refer to what is important.

Moving away from such time-oriented regimentation does not necessarily imply making out-of-house activities invisible, but instead might mean that consultants would not have to assess all activities in relation to billable hours. When asked how their firm handles the time problem, most of the consultants in our study merely sighed. However, one of these individuals who had just started working in the firm quoted above, (that had just introduced a system of measuring time in terms of productive hours), stressed:

I don't have to hide time spent on service forum activities under administration or some kind of desk research. It is simply called service forum. So, it is visible in the system and accepted that we spend time on this forum. I think that it is an example of how well the company has resolved the problem of spending time on nonbillable activities.

Knowledge sharing can easily be neglected in everyday practice - even though KM has been appointed a focus area in mission statements etc. - if the infrastructure of the company does not support it. It requires a shift in the attitude among the employees to integrate knowledge sharing in all aspects of job performance, and this shift can only be provoked if the way daily practice is valued, measured and talked about changes as well.

Another problem that the consultants pointed to in relation to time is the question of tailoring or recycling services. The ability to offer customized services is a strong value in the management-consultant business, as reflected in almost all of the management consulting firms' PR material:

- Services are tailored to meet specific and individual needs

- ... [we focus] on the specific preconditions and characteristics of your company in order to create and utilize new opportunities.

The desired image is that the services offered are not pre-packaged, off-the-shelf responses. Solutions and services are always tailored to match the needs of the client. Thus, the underlying assumption is that selling standardized consulting services does not have the same attraction as customized services. Clients must believe that they are unique, but this also signals to the consultants that they have to "start from scratch" in each engagement.

This orientation creates a paradox with respect to knowledge management. The purpose of knowledge sharing in management consulting firms is to recycle as much knowledge as possible (by storing concepts and tools that are accessible to everybody), in essence making it unnecessary to start from scratch every time. The reality is that most management consulting firms are selling standardized services adapted to meet the requirements of the individual client - meaning that the term "customized" should be taken "with a grain of salt."

It is difficult for the consultant to make the two ends meet - meeting the client's expectation for a unique product, while turning a standard product into a custo mized service. The consultant is caught in a dilemma. He or she wants to furnish the client with a tailor-made solution, making the client more than satisfied (one of the consultants' biggest fears is that their solution does not make a difference, and that the client company just continues on as if nothing happened). At the same time, due to the emphasis on billable hours (time registration) the consultant is forced to recycle solutions.

On top of this dynamic, it is important to bear in mind that knowledge workers prefer professional challenges and the ability to influence their day-to-day work activities. Thus, they are tempted to create unique solutions, even though a database may offers recipes that have already been served by colleagues, ready to be recycled. An HR manager of an 
engineering firm claimed that the company's engineers often delivered more than they were asked - and paid - to do. This was due to the fact that the engineers often turned (routine) assignments, where old solutions could be applied, into a greater challenge, where new knowledge could be developed. This urge for professional challenges seems to be a common trait for knowledge workers in particular, and is often neglected by ma nagement.

\section{The Problem of De-contextualization in Electronic Databases}

The assumption has gradually gained ground that knowledge stored as text in a database is not necessarily the same when it is retrieved by someone else, simply because we perceive, understand and interpret information differently. When sharing knowledge stored electronically, the best-case scenario is that different perceptions of the same information result in new and innovative knowledge. The worst-case scenario is that the information is misinterpreted, leading to genuine mistakes. One consulting firm, for example, reported that assessment tools stored on their Intranet were downloaded and used by someone from another department who did not have the authority or the necessary prerequisites for using them. The outcome could have been disastrous, but was not in this case.

The empirical data of our study questions the usability of stored knowledge. There are many indications of the dubious value of explicit knowledge (in terms of textual depiction) as reflected in the following statements made by respondents in different management consulting firms:

- It is my experience that writing down our ideas is minimally helpful - I can consult the system, but I do not learn anything from the model I see. I learn from what somebody explains to me about the model or the tool. Then I suddenly understand... just look at the one [model] I got from [department]. If I had just looked at it, my response would have been, 'oh, well.' But when I looked at it together with someone who briefly commented on it, I realized, 'wow, this is brilliant!'

- What other people have done seems alien to you. But you can use the information stored in the database for inspiration.

- Even though, as a project manager, you run into a lot of problems that interest many colleagues - if you had to summarize your experience in one page I don't know whether the account would be too fuzzy for anybody to make sense of it. I really don't know.

Management consulting firms are well known for their excellence in orienting new employees to the company, during which they are presented with company values and "the way we think here." Thus consulting firms attempt to create a common language, to the point where employees feel there is "a common understanding of what things represent here," presumably minimizing the risk of misinterpretation and error. However, as the above quotations reflect, colleagues are not necessarily able to exploit the knowledge of others just because it is written down. Within knowledge management, the latent assumption has been that as long as knowledge is made explicit and available everything is all right. It gives people access to knowledge, which they are able to employ as it is. Yet, as the quotes suggest, this is not always the case. If knowledge is to be understood as information applicable by others, the level of detail must be extremely high - and even then one cannot be sure that the textual information will answer all the reader's questions, especially to the point where he or she will be able to effectively act on that knowledge. Unfortunately, as the required detail level of the text increases, it is often perceived as taking up too much time to produce, raising the question of utility value.

Communication personnel operate with a three-tier structure in relation to the effects of good communication when planning a campaign (Sepstrup, 1999). First, you change 
people's knowledge by telling them something they did not know in advance. Since they may not necessarily agree, effective communication is also about making people change their attitude(s) - preferably on the basis of the new knowledge they have been given. A changed attitude is, however, still not sufficient for communication to succeed - the recipient must also change behavior, which can be very difficult to achieve. Similarly, there are a number of steps that the employee (being a recipient) must go through in order to be able to successfully use stored documents in a database: Does the recipient understand the message? Does the recipient agree? Would the recipient prefer to use the knowledge rather than inventing his/her own?

The problem most frequently cited within knowledge management is the challenge of turning tacit knowledge into explicit knowledge - and the solution so far has been documentation, documentation, documentation. The question remains as to whether this "solution" is the right way of approaching the problem. The case of Shell is an excellent illustration of the decontextualization ${ }^{4}$ issue. During the mid-nineties, Shell decided to create a database, a skill-pool based on their document archives of past assignments and problem solutions. Several years and a million dollars later, the company found that no one made use of the system. Whenever employees had a problem, they turned to colleagues instead of the database. Shell discovered that the employees wanted contextual answers, i.e., answers that corresponded with the specific problems they were experiencing. Drawing on this insight, Shell developed eleven mega-communities of practice across the world. Whenever employees have problems, they pose their questions online within their community, and, in general, receive an answer from a colleague within three hours, and usually three to four answers from different colleagues are submitted to each question. The answers are personal ("I had a similar problem, see the attached file but notice on page 15, that...") and hence are viewed as more contextual in nature.

Our study also shows, that people typically find that the most valuable knowledge sharing takes place while talking to colleagues:

Really, the most important source and perhaps biggest source of inspiration is actually person-to-person communication, which is the most important means of knowledge sharing. Nothing can replace it-neither systems, post-its, or slogans....

As this brief quote suggests, knowledge sharing is an activity that requires dialogue, at least before you can start acting upon the knowledge acquired (see also Apostolou \& Mentzas, 1999; Davenport \& Prusak, 1998). Several of the respondents talked about knowledge sharing as being most valuable when meeting a colleague and talking together about a specific problem or assignment. When knowledge sharing is linked to a purpose, the necessity is embedded in the present situation:

[Knowledge sharing] is indeed linked to special people and tied to certain situations in which you jointly must prepare some kind of client proposal ... It actually takes some time to talk each other into a level of knowledge sharing that works, and it does take the equal amount of time to establish a situation in which you can be mutually creative and stimulating. It isn't just there, it is something that has to be build up nicely and quietly... I don't do it with just anybody.

As another respondent emphasized, dialogue is one of the most informative types of communication, as it includes all senses:

Being [physically] together when sharing knowledge you capture more aspects as your questions can be clarified immediately. You 
can see the look on their face and how they act when telling their stories.

\section{Communication modes and knowledge sharing}

Figure 1 illustrates different means of communication ranked by degree of dialogue and thus of active knowledge sharing. At the bottom of the figure, the degree of dialogue is low. There is not much dialogue in stored documents or information passed on as one-way communication. Although text-based, the Intranet is more contextual than documents in databases as hyperlinks can help set a piece of information into a larger context. Mail can be viewed as a kind of dialogue although "delayed," as the recipient does not always answer immediately. When mail is used as a means of mass communication, the personal dialogue is not inherent, but still possible since the recipient always has the opportunity to reply. Electronic chat is written dialogue; it is oral language made textual, the exchange is immediate, and different emoticons (signs) help communicate the sender's feelings and body language/facial expressions - such as various "smileys" (e.g., :-) signaling happiness or :-( indicating displeasure) and predefined expressions (e.g., ROFL which is short for rolling on floor laughing) shared by peers in the virtual community.

\begin{tabular}{|l|l|}
\hline High degree & Face-to-face \\
\cline { 2 - 2 } & Videoconference \\
\cline { 2 - 2 } & Telephone \\
\hline \multirow{3}{*}{ Low degree } & Electronic Chat \\
\cline { 2 - 2 } & Mail \\
\cline { 2 - 2 } & Internet/Intranet \\
\cline { 2 - 2 } & Document databases \\
\hline
\end{tabular}

\section{Figure 1: Different Means of Communication, Ranked by Degree of Interpersonal Dialogue}

The videoconference is the only electronically mediated communication form that includes "physical" interaction, and, therefore, has a great potential - especially as bandwidth becomes standard. Dave Snowden proposes that we should manage what we say instead of what we write - as a way of sharing context instead of simply focusing on content. ${ }^{5}$. Videoconferences and video-clips on the Internet and company Intranets will certainly help achieve this goal.

If dialogue is defined by the spoken word, face-to-face interaction is the means of communication where the sharing of complex knowledge is most valuable. This does not mean that databases and corporate intranets are useless knowledge management tools. The point is that different modes of communication are suitable for different types of knowledge sharing, which will be elaborated at the end of this chapter.

\section{The Importance of Trust}

The concept of trust is fundamental to successful knowledge sharing - and is perhaps therefore often neglected or presupposed in knowledge activities. As illustrated by the comments of one of the respondents, the study shows that trust is a key concept in relation to several aspects of knowledge sharing:

Being among people that you like also facilitates the wish to show vulnerability - that there is something that you don't know and you are not afraid of showing it if you trust the people you are with. 
And you are not afraid of giving feedback even though it is harsh.

So it does create a different environment.

It can be vulnerable to show your ignorance - and, perhaps, especially in a culture, where the vending of knowledge is the core business. Therefore, knowledge employees tend not to like exhibiting their ignorance by seeking advice or asking what might be perceived as "silly questions." It also requires trust to critically evaluate the knowledge forwarded by colleagues, which is important in order to prevent a culture of "back scratchers" from emerging. Unless sufficient trust is embedded in the organization, these realities may subsequently lead to substandard results.

In addition to such explicit issues surrounding trust, many employees are humble about their competencies and performance. (This might be a cultural trait specific to Denmark. Employees in international companies mention that they don't recognize this behavior among their American colleagues). Such self-criticism was widespread in our study, creating a real barrier to knowledge sharing:

- And several times I have realized, that the things I've been working with - if I had to do them again I would do it differently. I can see it already - next time I will do it differently. And then I don't feel like uploading the deliverables from that assignment.

If you don't find it good enough compared to what you are able to?

- Yes.

In a time with access to more information than ever before - many large companies operate with more than a thousand different databases - the interviews seem to reflect a sense of powerlessness. As one of the respondents noted:

It is also a matter of how humble you are about what you have produced - of whether you think that your way of approaching the task is completely novel compared to what is already stored everywhere.

Other studies also show that self-criticism, post-rationalizations and a "who-do-you thinkyou-are-attitude" reduce the personal communication of knowledge (Henriksen, 2001).

Finally it requires trust to (re)-use other people's knowledge - especially when stored in a database. As mentioned earlier, making use of existing knowledge presupposes that you understand and agree with the material presented. This willingness often requires professional respect for and trust in the person who produced it. As reflected by the comments of a consultant in the study, it also requires trust in the system - is the knowledge in question updated or is there a better piece of information elsewhere?

Really, my experience with [the joint files] is that you have to ask questions anyway. If it is an issue with which you are not totally familiar, you have to ask anyway: Is this the last version and where precisely can I find something about this and this.

Trust is created through social activities:

Being together is very important to ... well to professionalism - to be able to give proper feedback. And to be able to ask in the right way about the right things.

Reflecting on why such interpersonal interaction is so important, another consultant explained:

I profit more from knowledge sharing with people who I know well, that is, people that I have talked with. We do not necessarily have to be personal friends; it just has to be that for some time we have had contact with each other, there is some kind of socializing and 
language creation in it. So, you've got to get to know each other, and begin to understand the other person's words. Then things start rolling.

Because knowledge sharing, to a large extent, involves creating social relations and informal talks between colleagues, coffee breaks and corridor chats should be viewed positively rather than as situations to avoid. Whether social activities take place during formal settings, such as workshops and seminars, or informal settings like lunch breaks and other social gatherings, the study shows that the social life of the organization is a strategic element with respect to knowledge sharing.

\section{Incentive Systems: Beyond Financial Rewards and Promotions}

The knowledge management literature often emphasizes that incentives are decisive for successful knowledge management projects (cf. Davenport, et al, 1998; Hanley, 1999; McDermott, 2001). Employees need incentives to be motivated to contribute their knowledge to the community and exploit the knowledge already available. Traditionally, incentives equal bonus and promotion, i.e., visible testimonials that it is advantageous to share knowledge both economically and career-wise. However, companies in our study that have implemented such incentive systems already, e.g., in connection with performance appraisals, still have problems with motivating organizational members and related barriers to knowledge management.

The study indicates that such incentive systems should expand beyond financial and promotion-based rewards. When respondents were asked directly what would make them share (more) knowledge, only a few mentioned a cash bonus. While this reaction may reflect a socially-desirable response bias (it is possible that they were reluctant to show that money matters), they focused on culture, structure and management. As mentioned earlier, it appears that a knowledge management orientation must be a part of the company culture - that it matters whether you do it or not:

The idea that when everybody does it, and if you are expected to do it - then it will be done, but there are no real expectations that it is done [from the management and the project manager].

Knowledge sharing should be incorporated into daily procedures and routines, thus making it an intrinsic part of the work and not an extracurricular, time-consuming activity:

There should be a structured access securing that everybody just does it. It is the same as when you start a project; you start a quality assurance procedure, you open a file and you do lots of things. The other part - closing down the project - should be just as integrated into the project.

One firm, for example, is experimenting with integrating its sales system with a documentation database. It is not possible for the project manager to close a job and invoice the client before the project is documented, as the system does not release the job code where the job expenses are invoiced. This process-oriented approach is intended to embed the knowledge sharing process into the basic way in which work is carried out in the firm.

There are other ways of building incentives into the system, although they are subtler. We often tend to see behavioral changes as an information problem - as long as people are told why they should change behavior and how, everything will work out. Sometimes, however, it is more appropriate to start the other way around. As reflected by the following interview, this can be done through a structural (organizational) change where employees are assigned new roles and are thus forced to act differently: 
- Before there was a tendency to keep your knowledge, your competence to yourself. And if somebody came and asked, can I borrow some slides, people would react a bit reserved...

Why was it like that?

- Because if you had developed a concept, then the others shouldn't just think that they could run around delivering it. First of all, they have to know something about it, secondly it is my design, it provides my 'bread,' and I was involved in the development. So it becomes small one-man firms, and you keep your knowledge to yourself.

What created that orientation?

- ... the only thing our incentive structure was based on was booking and delivery.

What created the change in attitude?

- Today, our incentive structure has become much more varied. There are now several ways of being successful and this helps deconstructing the knowledge hoarding behavior.

This management consulting firm shifted to an organizational structure where some consultants sell, others deliver and others develop, giving the consultants new roles. The role of the experienced consultants (who in the past had kept their knowledge to themselves) was changed to one of pure sales functions to take advantage of their client network. Suddenly they became dependent on the rest of the organization because they needed to consult with their colleagues who delivered the jobs: "The new role has resulted in different needs, and all of a sudden they have started to ask questions!"

Another of the firms in our sample is very committed to train new consultants in using the firm's databases and knowledge universe. This focus appears to have had a positive impact on the knowledge culture:

I think it is a question of time, training and insight. That they [the consultants] become attentive. And they [the newcomers] don't just sit in one department, they are spread all over the organization. It is very clear that in some departments they have communicated that knowledge [about the systems] to the older consultants - who have had their jobs for a long time - by saying: Look here... And then they [the older consultants] also change.

Finally, employees expect that management will define the guidelines for how and when knowledge sharing is appropriate in the specific organization. Confusion about fundamental questions like these can also prevent an effective knowledge culture from emerging. "The table must be laid" as one of the respondents pointed out, and another respondent explained:

We must have some rules. There need to be some frames and some things that are indisputable, and other things have to be much more value based. 'OK, I'll document, if I want to. You document, if you'd like to" - really, you can't have that as a value. You just have to say, 'Alright - in any case we do have to document this, this and that.

In sum, knowledge sharing needs to be an integral part of the core business ("what we do") and integrated into daily routines ("how we do it"). Such change requires the full support of top management. 


\section{Top Management Support}

Experience shows that if top management does not fully support a project on knowledge sharing it will not achieve the impact needed in order for it to become successful and thus valuable to the organization (cf. Davenport, et al, 1998; Earl \& Scott, 1999; Foote, et al, 2001). Our study also shows, that to create a culture where knowledge sharing is legitimate and desirable, management should first and foremost act as role models. As illustrated by the comments of one of the respondents, however, this is not always the case:

One thing I miss around here, is the partners socializing. Again, they create the frames but why on earth don't they participate in these [social] things? You can't force management to do so, but it is a damned good signal.

While top management in consulting firms seems to acknowledge the value of knowledge management, there appears to be a discrepancy between the stated goals, company practices and resource allocation when it comes to reality.

In management consulting firms, it is frequently the case that practice (behavior) counteracts the signal value of the messages originating from top management. The right words are followed by wrong actions, which only confuses the overall picture and understanding of the firm's goals and how they should be achieved: At the same time management provides ample arguments in support of the necessity and importance of knowledge sharing, but the organizational setup places an emphasis on billable hours and allows employees to hoard knowledge. The following remark by an employee indicates the importance of upper management in the managerial process:

We have a management that really prioritizes it [knowledge
management], and to a very high degree are exponents of this
enormous - you can say knowledge sharing, openness,
communication, etc. That's decisive. We could live in a box, we
can close down our net and we would exist anyway. That is my
hypothesis.

An interesting point in the study in relation to management concerns the discussion of whether a firm should have a Chief Knowledge Officer (CKO) (or Knowledge Manager, as some companies entitle the function) or not. In general, our findings suggest that the advantages of having a CKO compensate for its disadvantages. The firms with a CKO (or similar position responsible for knowledge management) are much more dedicated to initiatives in the knowledge area, have a more vivid knowledge culture (e.g., employees who are judged to be more conscious about knowledge sharing), and understand the value of both contributing to and exploiting the knowledge base in the organization. Although it is a general belief that knowledge management should be decentralized and "everyone's responsibility" through the creation of a knowledge culture, studies indicate (cf. Earl \& Scott, 1999; Foote 2001) that unless there is a person responsible for initiatives in the knowledge field, it is easily "nobody's responsibility" and organizational acceptance is weak.

\section{(RE)-DEFINING KNOWLEDGE SHARING}

The empirical data in our study indicate that the concept of knowledge sharing is both una mbiguous and manifold. Unambiguous in the sense that technology plays such an important part and manifold because the conceptions of what constitutes or should constitute knowledge sharing are multi-faceted. Knowledge sharing covers a variety of activities: a talk with a colleague at the coffee pot, an educational situation, a document in a database, an email, an information board with notices, and so forth. As such, knowledge sharing takes place each time you communicate who you are, what you are doing, or what you know to somebody else. 
Based on our study, it is possible to crystallize the concept of knowledge sharing (KS) in a number of sub-categories, creating a knowledge sharing typology (see Table 2).

Knowledge sharing is, to a high degree, about communication and thus concepts such as sender, recipient, message and medium (or channel of communication) are highly relevant. Since the message is influenced by the medium through which it is conveyed, it is important to offer as many channels of communication as possible, so that the sender can "choose" (not necessarily a conscious act) the optimal channel related to message, recipient and distance (time/space).

\begin{tabular}{|l|l|l|}
\hline Knowledge storing & Objective & Example \\
\hline Knowledge distribution & Availability & $\begin{array}{l}\text { Intranet } \\
\text { Databases } \\
\text { Binders }\end{array}$ \\
\hline Knowledge exposure & Prevailability & $\begin{array}{l}\text { Corporate news sites } \\
\text { Staff journals } \\
\text { Mass mail }\end{array}$ \\
\hline Knowledge transfer & Visibility & $\begin{array}{l}\text { Posters } \\
\text { Notice boards } \\
\text { Visible testimonials of the } \\
\text { company's production }\end{array}$ \\
\hline Knowledge exchange & Education & $\begin{array}{l}\text { Class room training } \\
\text { e-learning } \\
\text { Lectures } \\
\text { Presentations }\end{array}$ \\
\hline Knowledge collectivism & Communication & $\begin{array}{l}\text { Video conferences } \\
\text { Telephone } \\
\text { Chat } \\
\text { Mail }\end{array}$ \\
\hline & & $\begin{array}{l}\text { Mentorships } \\
\text { Communities of practice } \\
\text { Informal talks } \\
\text { Meetings }\end{array}$ \\
\hline
\end{tabular}

\section{Table 2: A Typology of Knowledge Sharing}

The typology of knowledge sharing is presented as a starting point for revising the way in which we think about the concept of knowledge sharing and its different possibilities and limitations. The purpose is to provide a more grounded platform for understanding the different means available in the knowledge sharing processes. It is assumed that the ambiguous nature of knowledge sharing prevents many people from using or practicing the concept, as they seek to reduce the complexity of knowledge sharing by simply focusing on one or two of the approaches in Table 2. Such emphasis is not deliberately intended to neglect the other aspects, but rather emerges from the reality that our perception of the types of knowledge sharing that have the biggest impact on efficiency and productivity - and thus value creation - is too narrow. When acts are made visible they are legitimated, and visibility and value are often equated. Knowledge materialized in a database is more tangible than knowledge inside people's heads or knowledge "floating" between colleagues in everyday interactions. However, the invisible and intangible knowledge, which is abundant among employees, create just as much - if not more - value for the firm. 
Several firms in our study were aware of this paradox and emphasized that their knowledge management initiatives are still only at a starting point. As a first step, most have focused on the tangible aspects of knowledge, especially in terms of implementing systems and procedures to strengthen knowledge flows within the firm. While efforts to deal with explicit, tangible knowledge clearly have their limits, this starting point is an important foundation for working with the softer, more intangible issues of knowledge sharing. As several firms in our study have indicated, the next steps in the area of knowledge management will be to work on more implicit, cultural issues.

\section{CONCLUSIONS}

This chapter has explored some of the parameters and problems constituting knowledge sharing in the management consulting business. The study shows that knowledge management in practice is still at a preliminary stage. Although there is a growing recognition of the value embedded in more systematic and holistic KM activities, many firms are still concerned with relatively fundamental problems in knowledge management. In fact, some of the firms in the study still only have a vague idea of what knowledge represents in their firms, thus making it more difficult to develop an appropriate strategy.

The study has reinforced that an explicit knowledge strategy and support from top management are key drivers in institutionalizing knowledge management processes in management consulting firms. Signals from top management that indicate what is expected from employees with regard to knowledge management clarify uncertainties and enhance action. The organizational infrastructure and the accompanying rhetoric also have a significant impact on firm culture and day-to-day activities, especially influencing the ways in which knowledge is shared and utilized. An over-arching emphasis on time utilization and billable hours counteracts knowledge management initiatives - especially when time utilization is linked to performance reviews - undermining the essence of knowledge sharing.

The study has illustrated that a knowledge strategy that is rooted in the business strategy and implemented throughout the organization and organizational processes serves as an incentive in itself. When knowledge sharing is a fully integrated part of the business, organizational members are more likely to think of knowledge sharing as an advantage rather than an obstacle - and therefore act accordingly. If interacting with colleagues is a prerequisite for successful job performance, employees are more likely to ask for and contribute knowledge when needed. Project organizations and related structures where colleagues are dependent on each other's work to achieve high-quality outcomes make it harder to hoard knowledge and create a small kingdom.

In this respect it is important to bear in mind that trust is an important factor when collaborating with others. There is a tendency, especially in management consulting firms, for knowledge employees to avoid any appearance of ignorance (by seeking advice or asking "silly questions"). They may also be reluctant to critically evaluate the knowledge forwarded by colleagues. Self-criticism and information overload are additional rationales that are often prevalent in the employee's mind. Organizational members prefer to share knowledge with people they know well and in connection to a current, specific problem.

The view of knowledge management proposed in this chapter shifts the emphasis on knowledge management processes from a technology-centric view to one where information technology acts as an enabling factor. It is not enough to simply make knowledge available, for example in databases, because it does not mean that the knowledge will be shared and utilized as intended. This is partly due to the fact that when knowledge is represented as a text in a document, it is decontextualized. "Man is a social animal" as Aristotle pointed out. People typically prefer talking to colleagues about problems rather than looking for solutions in databases. Even though the recipient who eventually reads the text may comprehend the 
words, it is not certain that the person will necessarily be able to effectively use the newly acquired knowledge. Since knowledge only has value in action, it is doubtful whether the efforts of documenting, quality assuring and updating documents in databases create the desired outcomes. While information technology will continue to play a significant role in knowledge management systems and knowledge sharing practices, the real challenge of knowledge ma nagement has been - and will continue to be - balancing the interplay between technology and people.

\section{NOTES}

1. The Proquest data base, which comprises many full journal articles as well as short magazine columns, provides a good representative sample of the current discussion in the field of management.

2. The information from these firms is considered as a secondary source because graduate students gathered it in a different context.

3. The use of photos is a relative new methodology in management research studies - or at least not extensively used - and a number of methodological issues could be raised. We have deliberately omitted a more profound discussion of the methodology in this paper, however, as our focus chosen is on content rather than form. This approach, however, raises some intriguing possibilities that could be incorporated into organizational ethnographies and field studies. It readily compensates for those situations where researchers may be too theoretically focused or where they are not very familiar with the organization.

4. The material on Shell was presented at the Knowledge Management Conference, $K M$ Europe 2001, in the Hague, the Netherlands, November, 2001.

5. Snowden's comments were made during a presentation at the Knowledge Management Conference KM Europe 2001, in the Hague, the Netherlands, November, 2001 .

\section{REFERENCES}

Allee, Verna (1997): The Knowledge E volution. E x panding O rganizational Intelligenœ. Boston: Butterworth-Heinemann.

Andresen, J. \& Jakobsen, S.L. (12-11-1999): "Genvej til videnstyring" in the daily business newspaper Børsen.

Apostolou, D. \& Mentzas, G. (1999). Managing corporate knowledge: A comparative analysis of experiences in consulting firms - Part I. Knowledge and Process Management, 6 (3): 129-138.

Badaracco, J.L. (1991). The knowledge link. Boston: Harvard Business School.

Blackler, F. (1995). Knowledge, knowledge work and organizations: An overview and interpretation. Organization Studies, 16 (6): 1021-1046.

Boisot, M.H. (1998). Knowledge assets: Securing Competitive advantage in the information economy. Oxford: Oxford University Press.

Christensen, P.H. (2001). Videnledelse i perspektiv - om udfordringer ved organisering og ledelse af viden. København: Samfundslitteratur. 
Cortada, J.W. \& Woods, J.A. (Eds.) (2000). The knowledge management yearbook 20002001. Woburn, MA: Butterworth-Heinemann.

Davenport, T., De Long, D. \& Beer, M.C. (1998). Successful knowledge ma nagement projects. Sloan Management Review, 39 (2): 43-57.

Davenport, T.H. \& Prusak, L. (1998). Working knowledge: How organizations manage what they know. Boston: Harvard Business School Press.

Dierkes, M., Berthoin, A.A., Child, J. \& Nonaka, I. (Eds.) (2001). Handbook of organizational learning and knowledge. Oxford: Oxford University Press.

Earl, M. \& Scott, I.A. (1999). Opinion: What is a chief knowledge officer? Sloan Management Review, 40 (2): 29-38.

Foote, N.W., Matson, E. \& Rudd, N. (2001). Managing the knowledge ma nager. The McKinsey Quarterly, (No. 3): 120-129.

Hanley, S.S. (1999). A culture built on sharing. Informationweek, 26-04-1999.

Hansen, M.H., Nohria, N. \& Tierney, T. (1999). What's your strategy for managing knowledge? Harvard Business Review, (March/April): 106-116.

Hauschild, S., Licht, T. \& Stein, W. (2001). Creating a knowledge culture. The McKinsey Quarterly, (No. 1): 74-81.

Henriksen, L. (2001). Videndeling - en forandringsproces snarere end en teknologisk udfordring - implementering af videndeling. Ledelse \& Erhvervsфkonomi, 65 (1): 2937.

Hildreth, P., Kimble, C., \& Wright, P. 2000, "Communities of practice in the distributed international environment", Journal of Knowledge Management, 4 (1): 27-38.

Kluge, J., Stein, W. \& Licht, T. (2001). Knowledge unplugged. New York: Palgrave.

Kvale, S. (1997). InterView: En introduktion til det kvalitative forskningsinterview. København: Hans Reitzels Forlag.

Little, S., Quintas, P. \& Ray, T.(Eds.) (2002). Managing knowledge. London: SAGE Publications Ltd.

McDermott, R. \& O'Dell. C. (2001). Overcoming cultural barriers to sharing knowledge. Journal of Knowledge Management, 5 (1): 76-85.

Mintzberg, H. (1983). Structure in fives. Designing effective organizations. Englewood Cliffs: Prentice-Hall.

Moberg, A. (1997). Närhet och distanc - Studier av kommunikationsmönster i satelitkontor och fleksibla kontor. Sverige: Linköping Universitetet.

Nonaka, I. \& Takeuchi, H. (1995). The knowledge-creating company. Oxford: Oxford University Press Inc. 
Polanyi, M. (1958). Personal knowledge. Chicago: Chicago University Press.

Saint-Onge, H. (1996). Tacit knowledge: The key to the strategic alignment of intellectual capital. Strategy \& Leadership, 24 (2): 10ff.

Sepstrup, P.(1999). Tilrettelaggelse af information. Århus: Forlaget Systime.

Storey, J. \& Barnett, E. (2000). Knowledge management initiatives: Learning from failure. Journal of Knowledge Management, 4 (2): 145-156.

von Hippel, E. (1990). The impact of "sticky" information on innovation and problemsolving. Working paper, no. 3147 - 90 - BPS. Cambridge, Massachusetts: MIT (Sloan School of Management). 